\title{
A Comprehensive Review of Overactive Bladder Pathophysiology: On the Way to
}

\section{Tailored Treatment}

Benoit Peyronnet ${ }^{\mathrm{a}, *}$, Emma Mironska $^{\mathrm{b}}$, Christopher Chapple ${ }^{\mathrm{b}}$, Linda Cardozo ${ }^{\mathrm{c}}$, Matthias

Oelke ${ }^{\mathrm{d}}$, Roger Dmochowski ${ }^{\mathrm{e}}$, Gérard Amarenco ${ }^{\mathrm{f}}$, Xavier Gamé ${ }^{\mathrm{g}}$, Roger Kirby ${ }^{\mathrm{h}}$, Frank Van Der Aa ${ }^{\mathrm{i}}$, Jean-Nicolas Cornu ${ }^{\mathrm{j}}$

${ }^{\text {a }}$ Department of Urology, University Hospital of Rennes, Rennes, France

${ }^{\mathrm{b}}$ Department of Urology, Sheffield Teaching Hospitals, Sheffield, UK

${ }^{\mathrm{c}}$ Department of Urology, St. Antonius Hospital, Gronau, Germany

${ }^{\mathrm{d}}$ Department of Urology, Vanderbilt University, Nashville, TN, USA

${ }^{\mathrm{e}}$ Department of Neurourology, Tenon Hospital, Paris, France

${ }^{\mathrm{f}}$ Department of Urogynaecology, King's College Hospital, London, UK

g Department of Urology, University Hospital of Toulouse, Toulouse, France

h The Prostate Centre, London, UK

${ }^{\text {i }}$ Department of Urology, University of Leuven, Leuven, Belgium

${ }^{j}$ Department of Urology, University Hospital of Rouen, Rouen, France

* Corresponding author. Service d'Urologie, Hopital Pontchaillou, 2 rue Henri Le Guilloux, 35000 Rennes, France. Tel. +33665717254.

E-mail address: peyronnetbenoit@ hotmail.fr (B. Peyronnet).

Keywords: Detrusor overactivity; Overactive bladder; Urinary incontinence; Urodynamics 


\section{Abstract}

Context: Current literature suggests that several pathophysiological factors and mechanisms might be responsible for the nonspecific symptom complex of overactive bladder (OAB).

Objective: To provide a comprehensive analysis of the potential pathophysiology underlying detrusor overactivity (DO) and $\mathrm{OAB}$.

Evidence acquisition: A PubMed-based literature search was conducted in April 2018, to identify randomised controlled trials, prospective and retrospective series, animal model studies, and reviews.

Evidence synthesis: $\mathrm{OAB}$ is a nonspecific storage symptom complex with poorly defined pathophysiology. OAB was historically thought to be caused by DO, which was either "myogenic" (urgency initiated from autonomous contraction of the detrusor muscle) or "neurogenic" (urgency signalled from the central nervous system, which initiates a detrusor contraction). Patients with $\mathrm{OAB}$ are often found to not have objective evidence of DO on urodynamic studies; therefore, alternative mechanisms for the development of OAB have been postulated. Increasing evidence on the role of urothelium/suburothelium and bladder afferent signalling arose in the early 2000s, emphasising an afferent "urotheliogenic" hypothesis, namely, that urgency is initiated from the urothelium/suburothelium. The urethra has also recently been regarded as a possible afferent origin of OAB - the "urethrogenic" hypothesis. Several other pathophysiological factors have been implicated, including metabolic syndrome, affective disorders, sex hormone deficiency, urinary microbiota, gastrointestinal functional disorders, and subclinical autonomic nervous system dysfunctions. These various possible mechanisms should be considered as contributing to diagnostic and treatment algorithms.

Conclusions: There is a temptation to label OAB as "idiopathic" without obvious causation, given the poorly understood nature of its pathophysiology. OAB should be seen as a complex, 
multifactorial symptom syndrome, resulting from multiple potential pathophysiological mechanisms. Identification of the underlying causes on an individual basis may lead to the definition of $\mathrm{OAB}$ phenotypes, paving the way for personalised medical care.

Patient summary: Overactive bladder (OAB) is a storage symptom syndrome with multiple possible causes. Identification of the mechanisms causing a patient to experience OAB symptoms may help tailor treatment to individual patients and improve outcomes.

\section{Introduction}

Overactive bladder (OAB) was defined in 2002 by the International Continence Society (ICS) as a storage symptom syndrome characterised by "urgency, with or without urgency urinary incontinence (UUI), usually with increased daytime frequency and nocturia" [1]. The ICS also acknowledged within this definition that these symptoms are usually "suggestive of urodynamically demonstrable detrusor overactivity but can be due to other forms of urethravesical dysfunction" [1]. This definition helped increase the awareness within the medical community regarding storage lower urinary tract symptoms (LUTS) and facilitated clinical research initiatives. Current guidelines propose a linear pathway, based purely on treatment invasiveness (conservative therapies and then drugs, minimally invasive surgery, and invasive surgery). However, the high rate of discontinuation of OAB medications [3] and the unclear results of recent randomised controlled trials (RCTs) comparing surgical options [4] highlight the limitation of this "one size fits all” approach.

Owing to the difficulty in identifying the underlying pathology for the development of OAB in most patients, it is often labelled as "idiopathic". Recently, it has been suggested that there are several subtypes of $\mathrm{OAB}[5,6]$. The aim of the present review is to provide an updated and comprehensive overview of the potential pathophysiology underlying $\mathrm{OAB}$, with the hope 
that describing clinical phenotypes may lead to a personalised approach to therapy.

\section{Evidence acquisition}

A PubMed-based literature search was conducted in April 2018, screening for RCTs, prospective and retrospective series, animal model studies, and reviews about OAB pathophysiology and management. The search strategy included the following terms: "overactive bladder", "urgency", "bladder overactivity", "storage symptoms", "pathophysiology", "aetiogenesis", and "mechanism", used alone or in combination. After removal of duplicates, two authors (B.P. and J.N.C.) independently screened the titles and abstracts of 5197 records for eligibility. The inclusion criteria were studies directly addressing the pathophysiology and mechanisms of $\mathrm{OAB}$, and their possible therapeutic implications. Studies addressing male benign prostatic obstruction and/or enlargement as well as bladder pain syndrome/interstitial cystitis were excluded. The full texts of 294 potentially eligible studies were retrieved and screened. A flowchart of the selection process is shown in Figure 1. Reference lists of articles selected in our initial search were also screened in order to identify other relevant manuscripts.

\section{Evidence synthesis}

Multiple contributory factors to $\mathrm{OAB}$ phenotypes have been proposed, and several potential OAB subtypes have been identified (Supplementary Fig. 1) [5,6] based on the underlying mechanism or pathophysiology, as summarised in Table 1.

\subsection{Phenotyping according to urodynamic demonstration of detrusor overactivity}


Detrusor overactivity (DO) is defined as "a urodynamic observation characterised by involuntary detrusor contractions during the filling phase which may be spontaneous or provoked" [1]. DO has often been assumed to be synonymous with OAB [5]; however, the presence of $\mathrm{DO}$ in only $50 \%$ of female $\mathrm{OAB}$ patients has prompted further research to consider the existence of alternative mechanisms relating to the role of the urothelium, suburothelium, urethra, and central nervous system (CNS) in the pathogenesis of OAB [5]. This suggests that a "bladder afferent signalling" mechanism contributes to the OAB symptom complex. Each one of these mechanisms exerts their effect at different levels of the bladder afferent pathway, and we outline these various hypotheses below.

\subsubsection{Myogenic hypothesis: urgency originating from the detrusor}

The pioneering works of Brading suggest that DO-driven urgency is mostly related to myogenic dysfunction inherent to denervation-related supersensitivity. Drake et al [7] later proposed that DO may result from histological changes of the detrusor, leading to abnormal electrical coupling of smooth muscle cells so that physiological micromotions become synchronised into active involuntary detrusor contraction [8]. However, other data suggest that increased afferent signalling resulting from urothelial/suburothelial dysfunction may contribute to uninhibited detrusor contractions [9] or that DO could be initiated from changes in central neural control of the micturition reflex (see section 3.1.4). As the definition and diagnosis of DO are well standardised [1], this criterion has been regarded as a good candidate to profile $\mathrm{OAB}$ patients and has been investigated accordingly, but the results have been poor with regard to its impact on treatment outcomes [5,10]. Among the current treatment armamentarium, only the use of conservative management and vaginal application of oestradiol, antimuscarinics, sacral neuromodulation (SNM), or intradetrusor botulinum toxin injections are supported by level 1 evidence in patients with urodynamically proven DO 


\subsubsection{Urotheliogenic hypothesis: urgency originating from the bladder} urothelium/suburothelium

In the late 1980s, studies demonstrated that either DO or an abnormal perception of bladder filling could provoke the sensation of urgency [11]. Since then, several studies have shown abnormal detrusor sensory function in patients with $\mathrm{OAB}$ [12-14]. The growing body of evidence on the role of increased activity of bladder afferents $[9,15]$ supports the idea $[5,6]$ of urgency resulting from urothelial/suburothelial dysfunction in some patients, which may not manifest as DO. UUI may indeed be less frequent in this subgroup of patients, but urinary frequency may be more common $[13,16]$, and this is thought to be mediated by abnormal sensory and signalling properties of the urothelium and suburothelial fibroblasts $[9,15]$ as well as possibly sympathetic dysfunction (see section 3.2.6). Beyond the sensory function of the urothelium/suburothelium, spontaneous contractions of the mucosa itself, originating from the muscularis mucosae, have been suggested as a possible origin of urgency [17]. Drugs modulating the sensory pathways, bladder afferent firing, and release of neurotransmitters, such as botulinum toxin, $\beta_{3}$-adrenergic receptor agonists, or phosphodiesterase inhibitors, from the urothelium may be regarded as valuable options in these patients [18]. Although the mechanisms of action have not been fully elucidated, biofeedback [19], antimuscarinics [20], and SNM [21] have been shown to reduce bladder oversensitivity and may also be considered as interesting options to tackle these urothelial/suburothelial dysfunctions.

\subsubsection{Urethrogenic hypothesis: urgency originating from the urethra}

In the early 20th century, Barrington [22] described various component reflexes of micturition in cats. The second of theses reflexes was evoked by running water through the urethra, and 
resulted in a strong bladder contraction mediated through pudendal and pelvic afferent and efferent signals [22]. Using an animal model, Jung et al [23] found that activation of urethral afferents by urethral perfusion could modulate the micturition reflex and thus hypothesised that entry of urine into the proximal urethra in patients with stress urinary incontinence (SUI) may stimulate urethral afferents, inducing and/or increasing DO. Their findings were confirmed a few years later in healthy human volunteers with the hypothesis of an urethrovesical reflex [24]. Many patients experience urgency when moving from a sitting or lying position to a standing position. This sign has been postulated to be a clinical feature of $\mathrm{OAB}$ originated from the urethra [25]. These patients may not display DO on urodynamics, as the investigation is usually performed only in the sitting position and the catheter might partially seal the bladder neck. It could also be hypothesised that patient positioning during filling cystometry may influence involuntary detrusor contractions. Valsalva-induced involuntary detrusor contractions have been proposed as a way to unmask DO in these patients [26]. It is fairly well established that surgical repair of SUI improves storage LUTS in some patients with mixed incontinence [27], but the role of SUI surgery for isolated OAB (notably dry $\mathrm{OAB}$ ) in selected patients with "urethral urgency" has not been evaluated to date. Indeed, there is unlikely to be an appetite for such a trial, particularly if patients are already dry. Conversely, de novo urgency is reported to occur in over $10 \%$ of patients undergoing any form of surgery for SUI. In patients with pelvic organ prolapse, it has been postulated, as part of the integral theory, that urgency may result from a prematurely activated micturition reflex caused by a lax vagina's inability to support bladder neck/proximal urethra stretch receptors, which could explain the high rates of $\mathrm{OAB}$ symptom resolution after surgical correction of pelvic organ prolapse [28].

While primary deterioration of urethral tone has been advocated as a possible cause of OAB, the concept of urethral sphincter instability (ie, urethral pressure variation during bladder 
filling) has been proposed as another mechanism of urethra-driven urgency, which may be due to a lack of pudendal or central neurological control [29]. Some evidence supports the role of SUI surgery in patients with urethral pressure variation [30]. By reporting that patients with refractory OAB successfully treated with SNM had an immediate recurrence of both DO and urethral pressure variation after bilateral modulation of the pudendal nerves (which stimulates urethral function), Groenendijk et al [31] suggested that SNM might be a valuable option in patients with urethra-driven OAB. Duloxetine may hypothetically be an interesting option in patients with "urethral urgency" by increasing urethral tone and has been shown to be an effective treatment for OAB in an RCT [32].

Two other mechanisms of OAB symptoms due to severe SUI might be encompassed in this urethrogenic hypothesis. First, constant leakage in patients with severe SUI may result in a chronically underfilled, "defunctionalised" bladder. Such patients may develop artifactual DO or impaired compliance generating urgency [33]. Those bladder dysfunctions have been shown to resolve in many cases after surgical correction of SUI by restoring the physiological cycles of bladder storage and voiding [33]. The second mechanism would be pre-emptive urinary frequency to prevent incontinence episodes in patients with severe SUI.

\subsubsection{Supraspinal hypothesis: urgency originating from the brain and brainstem}

Central neural control of micturition has been studied extensively over the past few decades [34], and the decreased capacity to functionally integrate afferent information or reduced supraspinal inhibitory control on the micturition reflex has been suggested since the late 1990s as a possible pathophysiological mechanism of OAB with the emergence of functional brain imaging [35]. Increasing evidence supports the idea of two distinct subtypes of "brain OAB": one with and one without DO [36]. The insula (lower bladder volumes) and anterior cingulate gyrus/supplementary motor area (higher volumes) may be neural characteristics of 
urgency without DO, while the neural signature of DO seems to be deactivation in the prefrontal cortex [36]. The difference in supraspinal activity between OAB patients with or without DO was confirmed by Tadic et al [37], demonstrating that older age and a greater burden of white matter damage in patients with DO are associated with more severe functional urinary impairment. Several reports support the hypothesis that this "white matter disease" could be the anatomical substrate for the brain aetiology of OAB associated with DO, maybe through frontal hypoperfusion [38].

Behavioural therapies seem appropriate to treat "brain OAB" by offering the possibility of retraining the supraspinal network to function normally, as recently evidenced by Griffiths et al [39]. Interestingly, these authors observed two patterns of brain reactions to bladder filling and were able to predict a response or nonresponse to biofeedback [39]. SNM has been shown to influence activity in several brain areas involved in micturition control and to promote neuroplastic reorganisation of cortical activity [40]. Some evidence suggests that posterior tibial nerve stimulation (PTNS) could also trigger plastic reorganisation of the cortical network involved in micturition control [41].

\subsubsection{Detrusor underactivity}

Significant efforts have been made by the urological community over the past few years to define underactive bladder symptom complex as a new clinical entity [42]. While underactive bladder is considered to be the clinical correlate of urodynamically defined detrusor underactivity, the voiding symptomatology of detrusor underactivity has been shown to overlap with $\mathrm{OAB}$ and urgency was reported to be the most common symptom in patients with urodynamically proven detrusor underactivity (seen in over $50 \%$ of patients) [43]. Not surprisingly, underactive bladder symptoms are associated with an increased prevalence of urgency, UUI, and nocturia in a survey-based epidemiological study including 977 patients 
[44]. The occurrence of urinary urgency in patients with DO can also be attributed to the wellknown DO/impaired contractility entity [45], which, in this context, is no doubt related to increased postvoid residuals and the subsequent reduced functional bladder capacity. In addition, urgency in detrusor underactivity can be attributed to urinary tract infections (UTIs) secondary to chronic urinary retention [46] or the impact of such retention on the urinary microbiota (see section 3.2.5). Current data suggest that detrusor underactivity may result from urothelial/suburothelial dysfunction (urotheliogenic hypothesis) and/or from detrusor muscle dysfunction (myogenic hypothesis) [47]. Despite encouraging preliminary data on cholinesterase inhibitors, no treatment has yet been proved clinically effective in restoring detrusor contractility [48], and therefore, clean intermittent self-catheterisation is still regarded as the standard of care for these patients despite the fact that the effectiveness of catheterisation alone in relieving storage LUTS in such patients has not been assessed clearly [49]. Potential future treatments such as procontractile drugs or stem cell therapy are currently under investigation but remain hypothetical [49], and SNM has been shown to be helpful in patients with detrusor underactivity and $\mathrm{OAB}$ symptoms, especially in those with some residual detrusor contractility and DO [46].

\subsection{Phenotyping according to pathophysiological cofactors}

\subsubsection{Metabolic syndrome}

A link between metabolic syndrome and $\mathrm{OAB}$ has been demonstrated in many studies, especially between obesity and $\mathrm{OAB}[50,51]$. While this association was initially thought to be driven through benign prostatic hyperplasia/chronic prostatic inflammation [51], increasing evidence has shown that $\mathrm{OAB}$ occurs equally in both men and women with metabolic syndrome [50,51]. OAB may have its own pathophysiology in patients with metabolic syndrome, relying on increased mechanical load stimulating sensory afferents of the trigone 
and bladder neck, but also on oxidative stress, systemic inflammation, and insulin resistance that promote chronic pelvic ischaemia and urothelial dysfunction [50,51].

Most of the current established treatment options for OAB, such as antimuscarinics, SNM, and botulinum toxin, have been reported to be less effective in patients with metabolic syndrome, or at least less effective than in other patient populations [52-54]. In contrast, the $\beta_{3}$-adrenoreceptor agonist mirabegron, which was designed initially as an antiobesity drug [55], was found to be equally effective in both obese and nonobese OAB patients [56], and might be well suited for this patient population although dose adjustment may be needed [57]. In the first RCT to date assessing the role of phosphodiesterase inhibitors in female patients, daily low-dose tadalafil was reported to be an effective and well-tolerated treatment for OAB [58]. Considering the pathophysiological role of the inflammatory and oxidative stress pathways in patients with metabolic syndrome and $\mathrm{OAB}$, phosphodiesterase inhibitors might become a noteworthy therapeutic option in such patients, as supported by a growing number of animal model studies and preliminary clinical trials [59]. However, based on the available literature, treatments targeting obesity, such as weight loss programmes and bariatric surgery, may be regarded as the most effective therapeutic options by acting on the multiple mechanisms listed above, with cure rates for UUI being as high as $19 \%$ and $79 \%$, respectively [60-62].

\subsubsection{Affective disorders}

While the impact of OAB may predispose affected individuals to anxiety and depressions, some evidence suggests that emotional stress and a history of anxiety/depression may be risk factors for the development of $\mathrm{OAB}$ in women [63]. This is not surprising in view of the central processing of afferent impulses in the limbic region of the brain. Recent data provided a detailed assessment of the temporal relationship between these symptoms, and demonstrated 
the influence of emotional stress and affective disorders on the natural history of OAB [63]. Hence, there may be a bidirectional association between affective disorders and OAB, with common underlying biological mechanisms resulting in co-occurrence of both disorders. Corticotrophin-releasing factor (CRF) has been investigated as a possible common pathophysiological contributor to $\mathrm{OAB}$ and anxiety/depression [64]. The concomitant decrease in serum CRF levels and improvement of depression-induced OAB observed using a CRF receptor type 1 antagonist in a recent animal model study confirm this possible mechanism, while highlighting a possible therapeutic pathway for social stress-induced OAB [65]. Serotonin depletion has been postulated as another shared pathophysiological candidate for both anxiety/depression and $\mathrm{OAB}$, as its role in affective disorders is well established and several experimental studies have demonstrated that lowering of serotonin levels in the CNS was accompanied by urinary frequency and DO [66,67]. Duloxetine, a noradrenalineserotonin reuptake inhibitor, has been reported to improve significantly frequency and urgency in an RCT of female OAB patients [68] and may be a valuable candidate for the treatment of stress-induced OAB, as shown in animal studies [69]. Indeed, it is licensed for the treatment of depression at a lower dose than that studied for the treatment of SUI. Transient receptor potential (TRP) channel dysfunctions might also play a key role in the cooccurrence of affective disorders and $\mathrm{OAB}$ [70]. Central sensitisation, defined as increased responsiveness of nociceptive neurons in the CNS to normal or subthreshold afferent input, has recently been suggested as a last common pathophysiological cofactor of anxiety/depression and $\mathrm{OAB}$ [71]. Many of the pathophysiological mechanisms mentioned above may be common to social stress-induced $\mathrm{OAB}$ and functional gastrointestinal disorders/pelvic organ cross-talk OAB phenotypes (see section 3.2.5) [72]. Duloxetine, TRP vanilloid (TRPV) antagonists, or CRF antagonists may target shared biological underpinning of anxiety/depression and $\mathrm{OAB}$, and thus, might become treatment options for emotional 
stress-induced OAB. SNM is the most widely studied and properly assessed treatment in our current armamentarium in this population [73].

\subsubsection{Sex hormone deficiency}

The impact of sex hormone deficiency on the lower urinary tract in female patients has been clearly established with oestrogen and progesterone receptors demonstrated in the urethra, bladder, and pelvic floor muscles [74]. Epidemiological studies have supported the role of sex hormone deficiency in the aetiogenesis of LUTS, with up to $70 \%$ of women relating the onset of urinary incontinence to their final menstruations [74]. Several mechanisms could explain the role of oestrogen deprivation in the onset of urinary urgency such as increased detrusor contractility through Rho-kinase pathway activation, increased acetylcholine release, changes in urothelial afferent signalling, or increased connexin-43 expression $[74,75]$. OAB in these patients is commonly associated with UTIs and vulvovaginal symptoms such as vaginal dryness, itching, and dyspareunia, which have recently been defined as a symptom complex known as genitourinary syndrome of menopause [76]. According to the latest Cochrane metaanalysis, the use of vaginal oestrogen may improve urinary incontinence, especially UUI [77], although the relevance of this option might be questioned in women without vaginal atrophy. In an RCT, Nelken et al [78] reported similar effects when using a vaginal oestradiol ring or oral oxybutynin in postmenopausal women with $\mathrm{OAB}$ but with more side effects for oxybutynin, which reinforces the putative role of local oestrogen in these patients. The impact of menopausal status on the outcome of standard $\mathrm{OAB}$ treatments has not been evaluated except for mirabegron, with a recent prospective study reporting no influence of sex hormone levels on the clinical efficacy of the $\beta_{3}$ agonist [79].

In contrast to women, evidence regarding sex hormone deficiency as a causative factor of $\mathrm{OAB}$ in men is scarce, but experimental studies suggest that testosterone may decrease 
detrusor excitability [80], improve bladder wall fibrosis [81], and may impact urothelial mediator release [82], providing a rationale for a causative role of androgen deficiency in the aetiogenesis of OAB. Testosterone replacement has been shown to improve LUTS in male patients, unfortunately without detailed analysis of storage symptoms [83].

\subsubsection{Urinary microbiota}

Following advances in culture methods, recent data suggested that the human urinary tract contains microbial communities referred to as the urinary microbiota, challenging the old dogma that urine is usually sterile [84,85]. According to recent preliminary studies, the urinary microbiota may play a role in the pathogenesis of $\mathrm{OAB}$, although the mechanisms underlying the causative relationship, as well as its possible therapeutic implications, are still unclear [85]. Bacterial DNA [86,87] and a higher load of bacteria [88] are more frequently detected in patients with UUI, with possibly decreased urinary microbiome diversity $[86,88-$ 90]. Some Lactobacillus spp. (eg, Lactobacillus crispatus) may be markers of a healthy female bladder with a possibly lower Lactobacillus load in patients with UUI $[86,88]$. Owing to their acid-producing qualities, Lactobacillus spp. may protect the lower urinary tract by controlling the growth of more virulent bacteria unable to survive in an acidic environment. While intravaginally administered Lactobacillus has shown promise in preventing recurrent UTIs, no studies to date have investigated the role of Lactobacillus probiotics in OAB [86]. Several preliminary studies have suggested a significant impact of the urinary microbiome on the outcomes of various $\mathrm{OAB}$ treatments such as antimuscarinics or intradetrusor botulinum toxin injection $[87,88,91]$, with responders more likely to have fewer bacteria and a less diverse community at baseline in some of these studies [88]. This supports the idea that urinary microbiota-related $\mathrm{OAB}$ may not be treated effectively by conventional $\mathrm{OAB}$ treatments, although data from the three available studies are contradictory [91]. In a recent 
study, an aberrant urinary microbiome with less diversity was found to be positively correlated with higher levels of depression and anxiety [90], which suggests that urinary microbiota may have the same potential as the gut microbiota to communicate with the brain, notably eliciting central sensitisation. Hence, like the well-established brain-gut-microbiota axis, a brain-bladder-microbiota axis might also exist. Whether this axis could involve the same mechanisms of bidirectional communication (neurotransmitter release, immune system stimulation, etc.) and be integrated as part of a more global brain-gut-bladder microbiota axis through central sensitisation warrants further investigation, but could provide a better understanding of $\mathrm{OAB}$ syndrome (see section 3.2.5). In addition it is clear that in clinical practice UTIs are usually characterised by significant bladder storage symptoms.

\subsubsection{Functional gastrointestinal disorders}

The bladder and colorectum have the same embryological origin, both developing from the cloaca, and thus share spinally derived neural pathways with dichotomised afferents innervating both organs and converging at a single dorsal ganglion root, which allows mechanisms of communication between the bladder and the colon known as cross-talk [92]. These common neural pathways may also be the drivers of cross-sensitisation defined as sensitisation of afferent nerves of one of the pelvic organs due to an acute insult in the other [92]. The co-occurrence of urological and gastrointestinal functional disorders reported in numerous studies is thought to be underpinned at least partly by the pelvic organ cross-talk and cross-sensitisation mechanisms [92,93].

Several reports have suggested bidirectional relationships between $\mathrm{OAB}$ and faecal incontinence or constipation [92,93]. However, the gastrointestinal condition that has most frequently been inter-related to $\mathrm{OAB}$ is irritable bowel syndrome (IBS) [92-94], with a prevalence of IBS as high as $33.3 \%$ in patients with OAB [95], both disorders being 
characterised by increased frequency of visceral emptying due to increased sensation (urgency for OAB; pain and discomfort for IBS) [96].

There has been growing interest over the past few years on the possible role of central sensitisation in the co-occurrence of functional urological and gastrointestinal disorders [71]. This central sensitisation might be triggered by pelvic organ cross-sensitisation, with activation of peripheral neural pathways leading to an amplification of signalling in the spinal cord and brain [93]. However, some authors have recently suggested that central sensitisation could be a primary dysfunction affecting the co-occurrence of both gastrointestinal and urological functional disorders alongside affective disorders (ie, anxiety and depression) as part of a brain-gut-bladder axis $[71,72]$. This possible brain-gut-bladder axis-OAB phenotype might be induced by stress due to either psychological factors (eg, a previous traumatic event) or physical factors (ie, internal/external physical threat). While infection is a well-established internal physical threat that could cause stress, hypothetically the gut and bladder microbiota could be involved as causative factors through peripheral and central sensitisation, which would support the idea of a brain-gut-bladder-microbiota axis [71,72].

Treatments targeting the bladder or colorectum have been reported to improve or worsen functional disorders in the other organ [92,93], which may support the use of treatments that have been proved to target both the bladder and the bowel in this OAB phenotype, such as SNM or PTNS $[97,98]$. Recent studies have indicated the potential role of SNM/PTNS in treating IBS in patients with affective disorders [99], and selected data also support the role of SNM/PTNS in treating social stress-induced OAB $[32,68,69]$. Through this logic, duloxetine may also be a future therapeutic option in the management of patients with "brain-gut-bladder axis-OAB" by targeting central sensitisation. Treatments aimed at interfering with neurogenic inflammation underlying pelvic organ cross-sensitisation such as TRPV1 receptor antagonists 
or $\alpha_{1}$-adrenoreceptor antagonists might also be interesting therapeutic approaches to evaluate in this population.

\subsubsection{Autonomic nervous system dysfunction}

Sympathetic, parasympathetic, and somatic nerves are well-known determinants of lower urinary tract physiological functioning $[9,16]$ and are altered in several neurological conditions proven to be associated with lower urinary tract dysfunction (eg, Parkinsonism, multiple sclerosis) [100]. Blanc et al [101] were the first authors to hypothesise that subclinical autonomic nervous system dysfunction may be a causative factor of "idiopathic" OAB. A few years later, Choi et al [102] confirmed the hypothesis of an autonomic imbalance associated with $\mathrm{OAB}$. More comprehensive insights into this autonomic balance dysfunction were emphasised by Hubeaux et al [103] by assessing heart rate variability during filling cystometry. They reported the predominance of parasympathetic activity when the bladder was empty and a preponderance of sympathetic activity at the end of bladder filling in women with OAB [103], which could suggest that bladder filling induces a global sympathetic response in women with OAB. Interestingly, the same research group initiated another study, which demonstrated that sympathetic dysfunction might be predominant over parasympathetic dysfunction in $\mathrm{OAB}$ patients and that $\mathrm{OAB}$ patients with autonomic dysfunction may be less likely to exhibit DO on urodynamics [104]. While other studies demonstrated similar alterations of sympathetic activity in OAB patients [105], an association between $\mathrm{OAB}$ and increased parasympathetic activation has also been reported [106]. Interestingly, in a recent study, it was reported that antimuscarinics may decrease parasympathetic dysfunction while improving OAB symptoms in these patients [106]. In contrast, a recent report suggested that sympathetic dysfunction in $\mathrm{OAB}$ patients could predict a poor response to antimuscarinics and suggested a possible role of $\beta_{3}$ agonists to restore 
impaired sympathetic efferent pathway activation eliciting detrusor muscle inhibition [107]. The various autonomic testing tools available may then help tailor first-line treatment in OAB patients.

\subsection{How to identify the phenotypes}

Currently, the various OAB subtypes are mostly identified through an exjuvantibus management, failure of first-line treatments narrowing down the search towards the actual mechanisms/aetiologies, and proper treatment [6]. Hypothetical approaches to distinguish the different $\mathrm{OAB}$ patterns are outlined below, supporting a "prism" approach (Fig. 1). These assumptions regarding the diagnostic approach to these multiple OAB subtypes as well as their speculative therapeutic implications are displayed in Figure 2. Hypotheses on the diagnostic approach are put forward below, but are not meant to replace the European Association of Urology, American Urological Association, and International Consultation on Incontinence evidence-based guidelines in daily practice for now [2,108,109].

\subsubsection{Clinical examination and medical history}

It is likely that most of the profiling of OAB patients could be achieved through a thorough medical history and clinical examination. Indeed, a patient's medical history could specifically identify several of the pathophysiological cofactors mentioned above (metabolic syndrome, menopause, affective disorders, and gastrointestinal functional disorders). The use of dedicated questionnaires and scores might help in detecting and quantifying these important concomitant disorders (eg, Hospital Anxiety and Depression Score for affective disorders [110]). Thorough clinical interview and physical examination to identify pertinent signs and symptoms will aid in highlighting any underlying pathological mechanisms

contributing to $\mathrm{OAB}$. For example, one may identify specific components of metabolic 
syndrome (obesity, hypertension, etc.) and symptoms suggestive of andropause (erectile dysfunction, decreased libido, etc.) or menopause (especially vulvovaginal atrophy). It is also important to elucidate specifics regarding the nature of a patient's LUTS. The coexistence of voiding LUTS may suggest detrusor underactivity, while urgency on standing may suggest a urethral origin of urgency. The existence of urgency with or without incontinence $(\mathrm{OAB}$ wet vs $\mathrm{OAB}$ dry) could help in differentiating DO- versus hypersensitivity-driven urgency (and then hypothetically myogenic vs urotheliogenic dysfunction) [111] with possible therapeutic implications (eg, scant evidence to support the use of botulinum toxin in $\mathrm{OAB}$ dry patients) $[2,6]$. Uroflowmetry and measurement of postvoid residual would be of interest to help in the screening for detrusor underactivity.

Simple clinical autonomic nervous system testing (eg, heart rate variability, blood pressure response to standing, hand grip exercise, cold pressor test, etc.) may help identify subclinical autonomic nervous system dysfunction in OAB patients [101-107].

Clinical manifestations of central sensitisation could also be detected during clinical examination using a group of psychophysical laboratory techniques known as quantitative sensory testing [107].

\subsubsection{Urodynamics}

Computer-urodynamic multichannel investigation might be helpful in identifying the origin of urgency by assessing the presence of DO suggestive of detrusor or supraspinal cause (see sections 3.1.1 and 3.1.4). In contrast, bladder oversensitivity without DO may be the urodynamic feature of urothelial origin [11-15]. Standing DO, Valsalva-induced DO, or urethral pressure variations during filling cystometry may suggest urgency originating from the urethra [23-29]. The diagnosis of detrusor underactivity as a contributing factor of storage symptoms could be made from the urodynamic study [42-45]. However, the clinical 
relevance of such urodynamic phenotyping of $\mathrm{OAB}$ is questionable, as several series have reported similar efficacy of various OAB treatments in patients with or without DO [10]. Given the possible lack of statistical power and poor design of most of these studies, as well as the absence of data regarding the impact of more complex urodynamic features on treatment outcomes, the role of urodynamics in the diagnosis of OAB phenotypes would require further evaluation.

\subsubsection{Is further "futuristic" diagnostic testing needed?}

Hypothetically, some more complex testing might be of interest to identify OAB phenotypes; measurement of serum and urine concentrations of stress-related hormones such as CRF or cortisol may be used in the future to diagnose stress-induced OAB [5,64]. Measuring serum testosterone may help detect androgen deficiency as a contributor of $\mathrm{OAB}$ in elderly men [74]. Inflammatory markers such as serum C-reactive protein may be of interest to identify whether inflammation is involved in the pathophysiology of OAB $[50,51,92,112]$.

Functional brain imaging eventually coupled with urodynamics may provide supraspinal markers of the different "brain" OAB subtypes [35-37,113,114].

Urinary markers involved in LUTS pathophysiology have widely been studied over the past $10 \mathrm{yr}[115]$ and could theoretically point towards some OAB subtypes (eg, increased urinary levels of nerve growth factor and brain-derived neurotrophic factor may indicate urothelial/suburothelial "sensory" dysfunction or central sensitisation) $[13-17,71,115,116]$. Finally, 16S RNA sequencing and expanded quantitative urine culture could help in identifying the urinary microbiota [85].

While the interest of this elaborated testing in clinical research is obvious to enhance the understanding of the multiple pathophysiological contributors of $\mathrm{OAB}$, their role in daily practice in the future is unlikely due to practical and cost-effectiveness issues. 


\subsection{Discussion}

This report provides a comprehensive overview of $\mathrm{OAB}$ pathophysiology in an attempt to clarify the complexity underlying the concept of "idiopathic" OAB and to plead for a shift towards the more accurate nomenclature of multifactorial OAB. Clearly different mechanisms could provoke the sensation of urinary urgency. Increasingly, the evidence over the past few years has shown that metabolic syndrome [50], affective disorders [64], sex hormone deficiency [74], urinary microbiota [85], gastrointestinal functional disorders [92], and subclinical autonomic nervous system dysfunction [103] may all be associated with OAB, and that $\mathrm{OAB}$ could have its own specific pathophysiology within all these frameworks. We feel that a "prism" spectrum approach could help identify these various OAB pathophysiological features. Numerous clues in the literature indicate that such phenotyping of $\mathrm{OAB}$ may translate into improved treatment decision making and outcomes despite data being too scarce currently to assert that each phenotype would need a specific treatment algorithm. It is important to stress that these $\mathrm{OAB}$ subtypes are clearly not mutually exclusive and that they likely commonly overlap. This may provide a robust rationale for combination therapy, as it could tackle several mechanisms increasing the chance of therapeutic success.

Our report has several limitations. Although the ideas presented here have arisen from peerreviewed publications and reached consensus among a panel of recognised international experts in the field, the new concept is not based on high-level evidence studies. Nevertheless, we believe that the data presented here could be strong enough to challenge the relevance of the treatment algorithm described in current international guidelines [2,108]. Another drawback is that translating these concepts into daily clinical practice will require additional investigations that may be hampered by the lack of a standardised definition of the various $\mathrm{OAB}$ pathophysiological features as well as the lack of consensual techniques to diagnose 
these key contributing factors. Some exploratory therapeutic strategies of OAB such as antidiuresis with desmopressin could not be addressed in the way the present manuscript was designed, which could be regarded as a shortcoming [117]. Although we decided to exclude the role of bladder outlet obstruction and bladder pain syndrome in our hypotheses, this could be regarded as a significant limitation to the present review. This decision was made because the pathophysiological mechanisms underlying $\mathrm{OAB}$ symptoms in these clinical scenarios were deemed to largely overlap those of some phenotypes presented herein (myogenic, urotheliogenic, and detrusor underactivity for bladder outlet obstruction; affective disorders, urinary microbiota, and functional gastrointestinal disorders for bladder pain syndrome). However, one could consider that bladder outlet obstruction and bladder pain syndrome would fulfil the criteria to be considered as two additional OAB subtypes, especially with regard to their distinct therapeutic algorithms. Finally, the decision to consider equally OAB subtypes based on well-established pathophysiological mechanisms and those defined by the existence of pathophysiological cofactors could be a matter of debate, as in the latter case, one could question the link between each of these comorbidities and OAB symptoms in a given patient.

\section{Conclusions}

There is not one single form of $\mathrm{OAB}$ syndrome but rather several OAB phenotypes based on the underlying mechanisms and pathophysiological cofactors, supporting a paradigm shift in $\mathrm{OAB}$ towards treatment strategies that could be tailored to individual patient characteristics (Fig. 3). We believe that new studies should assess the outcomes of the current OAB treatments for each different $\mathrm{OAB}$ subpopulation, leading to more personalised medical approaches, particularly as we progress into the era of combination pharmacotherapy. The urological community, research organisations, health insurances, and governmental health 
authorities should promote studies looking at a personalised approach to OAB patients. Clearly from a public health standpoint, the cost effectiveness of a tailored versus a "one size fits all" treatment approach is evident, particularly based on the poor long-term compliance with existing pharmacotherapy.

Author contributions: Benoit Peyronnet had full access to all the data in the study and takes responsibility for the integrity of the data and the accuracy of the data analysis.

Study concept and design: Peyronnet, Cornu, Amarenco, Gamé.

Acquisition of data: Peyronnet, Cornu, Mironska.

Analysis and interpretation of data: Peyronnet, Mironska, Chapple, Cardozo, Oelke,

Dmochowski, Amarenco, Gamé, Kirby, Van Der Aa, Cornu.

Drafting of the manuscript: Peyronnet, Mironska, Chapple, Cardozo, Oelke, Dmochowski, Amarenco, Gamé, Kirby, Van Der Aa, Cornu.

Critical revision of the manuscript for important intellectual content: Peyronnet, Mironska, Chapple, Cardozo, Oelke, Dmochowski, Amarenco, Gamé, Kirby, Van Der Aa, Cornu. Statistical analysis: None.

Obtaining funding: None.

Administrative, technical, or material support: None.

Supervision: None.

Other: None.

Financial disclosures: Benoit Peyronnet certifies that all conflicts of interest, including specific financial interests and relationships and affiliations relevant to the subject matter or materials discussed in the manuscript (eg, employment/affiliation, grants or funding, consultancies, honoraria, stock ownership or options, expert testimony, royalties, or patents filed, received, or pending), are the following: Benoit Peyronnet is a consultant for Astellas, Allergan, Medtronic, and Boston Scientific. Christopher Chapple is a consultant, researcher, and speaker for Astellas, Allergan, Pfizer, and Medtronic; has received personal fees and nonfinancial support from Allergan and Pfizer; and has received grants, personal fees, and 
nonfinancial support from Astellas. Linda Cardozo has received funding for research or lecturing from Astellas and Pfizer, and for research consultancy and/or advisory work from Allergan, Astellas, BMR, Ferring, Pfizer, and Syner-Med. Matthias Oelke reports personal fees from Allergan, Bayer Healthcare, Biocompatibles, Ferring, and Mundipharma; personal fees and other from Apogepha; grants, personal fees, and nonfinancial support from Astellas and Pfizer; personal fees, nonfinancial support, and other from GlaxoSmithKline; personal fees and nonfinancial support from Lilly and Recordati, all outside the submitted work. Roger Dmochowski is a consultant/advisor for Medtronic and Allergan. Gérard Amarenco is a consultant and speaker for Astellas, Pfizer, Allergan, Laborie, and Wellspect. Xavier Gamé is a consultant for Astellas, Pierre Fabre, Allergan, Medtronic, and Ipsen. Frank Van Der Aa has spoken on behalf of and received honorarium from Astellas, Pfizer, and GlaxoSmithKline; and is a consultant for Medtronic, Allergan, and Astellas. Roger Kirby has been reimbursed by Astellas, GSK, Pfizer, and MSD for attending conferences, lecturing, and expenses of research studies. Jean-Nicolas Cornu is a consultant/speaker for Astellas, Pfizer, Boston Scientific, Medtronic, and Bouchara Recordati. Emma Mironska has nothing to disclose.

\section{Funding/Support and role of the sponsor: None.}

\section{References}

[1] Abrams P, Cardozo L, Fall M, et al. The standardisation of terminology of lower urinary tract function: report from the Standardisation Sub-committee of the International Continence Society. Neurourol Urodyn 2002; 21:167-78.

[2] Gormley EA, Lightner DJ, Burgio KL, et al. Diagnosis and treatment of overactive bladder (non-neurogenic) in adults: AUA/SUFU guideline. J Urol 2012;188(6 Suppl):2455-63.

[3] Chapple CR, Nazir J, Hakimi Z, et al. Persistence and adherence with mirabegron versus antimuscarinic agents in patients with overactive bladder: a retrospective observational study in UK clinical practice. Eur Urol 2017;72:389-99.

[4] Amundsen CL, Richter HE, Menefee SA, et al. Onabotulinumtoxin A vs sacral neuromodulation on refractory urgency urinary incontinence in women: a randomized clinical trial. JAMA 2016;316:1366-74.

[5] Roosen A, Chapple CR, Dmochowski RR, et al. A refocus on the bladder as the originator of storage lower urinary tract symptoms: a systematic review of the latest literature. Eur Urol 2009;56:810-9. 
[6] Apostolidis A, Averbeck MA, Sahai A, et al. Can we create a valid treatment algorithm for patients with drug resistant overactive bladder (OAB) syndrome or detrusor overactivity (DO)? Results from a think tank (ICI-RS 2015). Neurourol Urodyn 2017;36:882-93.

[7] Drake MJ, Mills IW, Gillespie JI. Model of peripheral autonomous modules and a myovesical plexus in normal and overactive bladder function. Lancet 2001;358:401-3.

[8] Hulls CM, Lentle RG, King QM, Reynolds GW, Chambers JP. Spatiotemporal analysis of spontaneous myogenic contractions in the urinary bladder of the rabbit: timing and patterns reflect reported electrophysiology. Am J Renal Physiol 2017;313:F687-98.

[9] Chapple C. Chapter 2: Pathophysiology of neurogenic detrusor overactivity and the symptom complex of "overactive bladder". Neurourol Urodyn 2014;33(Suppl 3):S6-13.

[10] Rachaneni S, Latthe P. Effectiveness of BTX-A and neuromodulation in treating OAB with or without detrusor overactivity: a systematic review. Int Urogynecol J 2017;28:805-16.

[11] Creighton SM, Pearce JM, Robson I, Wang K, Stanton SL. Sensory urgency: how full is your bladder? Br J Obstet Gynaecol 1991;98:1287-9.

[12] Yamaguchi O, Honda K, Nomiya M, et al. Defining overactive bladder as hypersensitivity. Neurourol Urodyn 2007;26:904-7.

[13] Lee SR, Kim HJ, Kim A, Kim JH. Overactive bladder is not only overactive but also hypersensitive. Urology 2010;75:1053-9.

[14] Blyweert W, Van der Aa F, Ost D, Stagnaro M, De Ridder D. Interstitial cells of the bladder: the missing link? BJOG 2004;111(Suppl 1):57-60.

[15] Roosen A, Chapple CR, Dmochowski RR, et al. A refocus on the bladder as the originator of storage lower urinary tract symptoms: a systematic review of the latest literature. Eur Urol 2009;56:810-9.

[16] Chen SL, Ng SC, Huang YH, Chen GD. Are patients with bladder oversensitivity different from those with urodynamically proven detrusor overactivity in female overactive bladder syndrome? J Chin Med Assoc 2017;80:644-50.

[17] Kushida $\mathrm{N}$, Fry $\mathrm{CH}$. On the origin of spontaneous activity in the bladder. BJU Int 2016;117:982-92.

[18] Kanai A, Zabbarova I, Oefelein M, Radziszewski P, Ikeda Y, Andersson K-E. Mechanisms of action of botulinum neurotoxins, B3-adrenergic receptor agonists and IPDE5 inhibitors in modulating detrusor function in overactive bladder: ICI-RS 2011. Neurourol Urodyn 2012;31:300-8.

[19] Wyndaele JJ, Hoekx L, Vermandel A. Bladder biofeedback for the treatment of refractory 
sensory urgency in adults. Eur Urol 1997;32:429-32.

[20] Vijaya G, Digesu GA, Derpapas A, Hendricken C, Fernando R, Khullar V. Antimuscarinic effects on current perception threshold: a prospective placebo control study. Neurourol Urodyn 2012;31:75-9.

[21] Oliver S, Fowler C, Mundy A, Craggs M. Measuring the sensations of urge and bladder filling during cystometry in urge incontinence and the effects of neuromodulation. Neurourol Urodyn 2003;22:7-16.

[22] Barrington FJF. The component reflexes of micturition in the cats, parts 1 and 2. Brain 1931;54:177.

[23] Jung SY, Fraser MO, Ozawa H, et al. Urethral afferent nerve activity affects the micturition reflex; implication for the relationship between stress incontinence and detrusor instability. $\mathbf{J}$ Urol 1999;162:204-12.

[24] Shafik A, Shafik AA, El-Sibai O, Ahmed I. Role of positive urethrovesical feedback in vesical evacuation. The concept of a second micturition reflex: the urethrovesical reflex. World J Urol 2003;21:167-70.

[25] Hubeaux K, Deffieux X, Desseaux K, Verollet D, Damphousse M, Amarenco G. Stand up urgency: is this symptom related to a urethral mechanism? Prog Urol 2012;22:475-81.

[26] Serels SR, Rackley RR, Appell RA. Surgical treatment for stress urinary incontinence associated with Valsalva induced detrusor instability. J Urol 2000;163:884-7.

[27] Jain P, Jirschele K, Botros SM, Latthe PM. Effectiveness of midurethral slings in mixed urinary incontinence: a systematic review and meta-analysis. Int Urogynecol J 2011;22:92332.

[28] Petros PE, Woodman PJ. The integral theory of continence. Int Urogynecol J 2008;19:35-40.

[29] Kirschner-Hermanns R, Anding R, Rosier P, Birder L, Andersson KE, Djurhuus JC. Fundamentals and clinical perspective of urethral sphincter instability as a contributing factor in patients with lower urinary tract dysfunction-ICI-RS 2014. Neurourol Urodyn 2016;35:318-23.

[30] Koonings P, Bergman A, Ballard CA. Combined detrusor instability and stress urinary incontinence: where is the primary pathology? Gynecol Obstet Invest 1988;26:250-6.

[31] Groenendijk PM, Heesakkers JP, Lycklama A, Nijeholt AA. Urethral instability and sacral nerve stimulation—a better parameter to predict efficacy? J Urol 2007;178:568-72.

[32] Steers WD, Herschorn S, Kreder KJ, et al. Duloxetine compared with placebo for treating women with symptoms of overactive bladder. BJU Int 2007;100:337-45. 
[33] Afraa TA, Campeau L, Mahfouz W, Corcos J. Urodynamic parameters evolution after artificial urinary sphincter implantation for post-radical prostatectomy incontinence with concomitant bladder dysfunction. Can J Urol 2011;18:5695-8.

[34] Holstege G, Griffiths D, de Wall H, Dalm E. Anatomical and physiological observations on supraspinal control of bladder and urethral sphincter muscles in the cat. J Comp Neurol 1986;250:449-61.

[35] Griffiths D, Derbyshire S, Stenger A, Resnick N. Brain control of normal and overactive bladder. J Urol 2005;174:1862-7.

[36] Griffiths D, Tadic SD. Bladder control, urgency, and urge incontinence: evidence from functional brain imaging. Neurourol Urodyn 2008;27:466-74.

[37] Tadic SD, Griffiths D, Schaefer W, et al. Brain activity underlying impaired continence control in older women with overactive bladder. Neurourol Urodyn 2012;31:652-8.

[38] Apostolidis A, Wagg A, Rahnam A'i MS, Panicker JN, Vrijens D, von Gontard A. Is there "brain $\mathrm{OAB}$ " and how can we recognize it? International Consultation on IncontinenceResearch Society (ICI-RS) 2017. Neurourol Urodyn 2018;37(S4):S38-45.

[39] Griffiths D, Clarkson B, Tadic SD, Resnick NM. Brain mechanisms underlying urge incontinence and its response to pelvic floor muscle training. J Urol 2015;194:708-15.

[40] Blok BF, Groen J, Bosch JL, Veltman DJ, Lammertsma AA. Different brain effects during chronic and acute sacral neuromodulation in urge incontinent patients with implanted neurostimulators. BJU Int 2006;98:1238-43.

[41] Finazzi-Agrò E, Rocchi C, Pachatz C, et al. Percutaneous tibial nerve stimulation produces effects on brain activity: study on the modifications of the long latency somatosensory evoked potentials. Neurourol Urodyn 2009;28:320-4.

[42] Chapple CR, Osman NI, Birder L, et al The underactive bladder: a new clinical concept? Eur Urol 2015;68:351-3.

[43] Uren AD, Cotterill N, Harding C, et al. Qualitative exploration of the patient experience of underactive bladder. Eur Urol 2017;72:402-7.

[44] Faraj K, Doo F, Boura J, Vereecke A, Chancellor MB. A cross-sectional study in the USA of the epidemiology and quality of life of underactive bladder symptoms. Int Urol Nephrol 2016;48:1797-802.

[45] Rademakers KL, Drossaerts JM, van Kerrebroeck PE, Oelke M, van Koeveringe GA. Prediction of sacral neuromodulation treatment success in men with impaired bladder emptying - time for a new diagnostic approach. Neurourol Urodyn 2017;36:808-10. 
[46] Kim DK. Origin of urgency symptom in underactive bladder: commentary on "underactive bladder: clinical features, urodynamic parameters, and treatment". Int Neurourol J 2015;19:293-4.

[47] Kerdraon J, Peyronnet B, Gamé X, et al. Pathophysiology of detrusor underactivity in the elderly. Prog Urol 2017;27:402-12.

[48] Smith PP, Tyagi P, Kuchel GA, et al. Advanced therapeutic directions to treat the underactive bladder. Int Urol Nephrol 2014;46(Suppl 1):S35-44.

[49] Gani J, Hennessey D. The underactive bladder: diagnosis and surgical treatment options. Transl Androl Urol 2017;6(Suppl 2):S186-95.

[50] Bunn F, Kirby M, Pinkney E, et al. Is there a link between overactive bladder and the metabolic syndrome in women? A systematic review of observational studies. Int J Clin Pract 2015;69:199-217.

[51] He Q, Wang Z, Liu G, Daneshgari F, MacLennan GT, Gupta S. Metabolic syndrome, inflammation and lower urinary tract symptoms: possible translational links. Prostate Cancer Prostatic Dis 2016;19:7-13.

[52] Richter HE, Amundsen CL, Erickson SW, et al. Characteristics associated with treatment response and satisfaction in women undergoing onabotulinumtoxin $\mathrm{A}$ and sacral neuromodulation for refractory urgency urinary incontinence. J Urol 2017;198:890-6.

[53] Lua LL, Pathak P, Dandolu V. Comparing anticholinergic persistence and adherence profiles in overactive bladder patients based on gender, obesity, and major anticholinergic agents. Neurourol Urodyn 2017;36:2123-31.

[54] Schneider T, Marschall-Kehrel D, Hanisch JU, Michel MC. Do gender, age or lifestyle factors affect responses to antimuscarinic treatment in overactive bladder patients? Int J Clin Pract 2010;64:1287-93.

[55] Hainer V. Beta3-adrenoreceptor agonist mirabegron-a potential antiobesity drug? Expert Opin Pharmacother 2016;17:2125-7.

[56] Krhut J, Martan A, Zachoval R, Hanuš T, Švabík K, Zvara P. Impact of body mass index on treatment efficacy of mirabegron for overactive bladder in females. Eur J Obstet Gynecol Reprod Biol 2016;196:64-8.

[57] Mossa A, Velasquez Flores M, Nguyen H, Cammisotto PG, Campeau L. Beta-3 adrenoreceptor signaling pathways in urothelial and smooth muscle cells in the presence of succinate. J Pharmacol Exp Ther 2018;367:252-9.

[58] Chen H, Wang F, Yu Z, et al. Efficacy of daily low-dose tadalafil for treating overactive 
bladder: results of a randomized, double-blind, placebo-controlled trial. Urology 2017;100:59-64.

[59] Ding H, Li N, He X, Liu B, Dong L, Liu Y. Treatment of obesity-associated overactive bladder by the phosphodiesterase type-4 inhibitor roflumilast. Int Urol Nephrol 2017;49:172330.

[60] Subak LL, Wing R, West DS, et al. Weight loss to treat urinary incontinence in overweight and obese women. N Engl J Med 2009;360:481-90.

[61] Ait Said K, Leroux Y, Menahem B, Doerfler A, Alves A, Tillou X. Effect of bariatric surgery on urinary and fecal incontinence: prospective analysis with 1-year follow-up. Surg Obes Relat Dis 2017;13:305-12.

[62] Luke S, Addison B, Broughton K, Masters J, Stubbs R, Kennedy-Smith A. Effects of bariatric surgery on untreated lower urinary tract symptoms: a prospective multicentre cohort study. BJU Int 2015;115:466-72.

[63] Vrijens D, Drossaerts J, van Koeveringe G, Van Kerrebroeck P, van Os J, Leue C. Affective symptoms and the overactive bladder-a systematic review. J Psychosom Res 2015;78:95108.

[64] Klausner AP, Steers WD. Corticotropin releasing factor: a mediator of emotional influences on bladder function. J Urol 2004;172:2570-3.

[65] Wróbel A, Doboszewska U, Rechberger E, Wlaź P, Rechberger T. SN003, a CRF1 receptor antagonist, attenuates depressive-like behavior and detrusor overactivity symptoms induced by 13-cis-retinoic acid in rats. Eur J Pharmacol 2017;812:216-24.

[66] de Groat WC. Influence of central serotonergic mechanisms on lower urinary tract function. Urology 2002;59(5 Suppl 1):30-6.

[67] Chiba H, Mitsui T, Kitta T, et al. The role of serotonergic mechanism in the rat prefrontal cortex for controlling the micturition reflex: an in vivo microdialysis study. Neurourol Urodyn 2016;35:902-7.

[68] Steers WD, Herschorn S, Kreder KJ, et al. Duloxetine compared with placebo for treating women with symptoms of overactive bladder. BJU Int 2007;100:337-45.

[69] Wróbel A, Rechberger E, Rechberger T. The influence of duloxetine on detrusor overactivity in rats with depression induced by 13-cis-retinoic acid. Int Urogynecol J 2018;29:987-995.

[70] Kaneko Y, Szallasi A. Transient receptor potential (TRP) channels: a clinical perspective. Br J Pharmacol 2014;171:2474-507. 
[71] Reynolds WS, Dmochowski R, Wein A, Bruehl S. Does central sensitization help explain overactive bladder. Nat Rev Urol 2016;13:481-91.

[72] Leue C, Kruimel J, Vrijens D, Masclee A, van Os J, van Koeveringe G. Functional urological disorders: a sensitized defence response in the bladder-gut-brain axis. Nat Rev Urol 2017;14:153-63.

[73] Killinger KA, Fergus J, Edwards L, et al. Coexisting depressive symptoms do not limit the benefits of chronic neuromodulation: a study of over 200 patients. Neurourol Urodyn 2018;37:815-22.

[74] Hanna-Mitchell AT, Robinson D, Cardozo L, Everaert K, Petkov GV. Do we need to know more about the effects of hormones on lower urinary tract dysfunction? ICI-RS 2014. Neurourol Urodyn 2016;35:299-303.

[75] Lee KC. Changes of muscarinic receptors and connexin-43 expression as a mechanism of overactive bladder in ovariectomized rats. World J Urol 2015;33:1875-9.

[76] Portman DJ, Gass ML; Vulvovaginal Atrophy Terminology Consensus Conference Panel. Genitourinary syndrome of menopause: new terminology for vulvovaginal atrophy from the International Society for the Study of Women's Sexual Health and the North American Menopause Society. J Sex Med 2014;11:2865-72.

[77] Cody JD, Jacobs ML, Richardson K, Moehrer B, Hextall A. Oestrogen therapy for urinary incontinence in post-menopausal women. Cochrane Database Syst Rev 2012;10:CD001405.

[78] Nelken RS, Ozel BZ, Leegant AR, Felix JC, Mishell DR Jr. Randomized trial of estradiol vaginal ring versus oral oxybutynin for the treatment of overactive bladder. Menopause 2011;18:962-6.

[79] Kallner HK, Elmér C, Andersson KE, Altman D. Hormonal influence on the effect of mirabegron treatment for overactive bladder. Menopause 2016;23:1303-6.

[80] Hristov KL, Parajuli SP, Provence A, Petkov GV. Testosterone decreases urinary bladder smooth muscle excitability via novel signaling mechanism involving direct activation of the BK channels. Am J Physiol Renal Physiol 2016;311:F1253-9.

[81] de Barros CA, Lorenzetti F, Ortiz V, Dambros M. Testosterone supplementation's effects on age-related bladder remodeling — experimental study in rats. Aging Male 2013;16:102-7.

[82] Bravo G, Massa H, Rose'Meyer R, Chess-Williams R, McDermott C, Sellers DJ. Effect of short-term androgen deficiency on bladder contractility and urothelial mediator release. Naunyn Schmiedebergs Arch Pharmacol 2017;390:547-56.

[83] Haider KS, Haider A, Doros G, Traish A. Long-term testosterone therapy improves urinary 
and sexual function, and quality of life in men with hypogonadism: results from a propensity matched subgroup of a controlled registry study. J Urol 2018;199:257-65.

[84] Drake MJ, Morris N, Apostolidis A, Rahnama'i MS, Marchesi JR. The urinary microbiome and its contribution to lower urinary tract symptoms; ICI-RS 2015. Neurourol Urodyn 2017;36:850-3.

[85] Aragón IM, Herrera-Imbroda B, Queipo-Ortuño MI, et al. The urinary tract microbiome in health and disease. Eur Urol Focus 2018;4:128-38.

[86] Pearce MM, Hilt EE, Rosenfeld AB, et al. The female urinary microbiome: a comparison of women with and without urgency urinary incontinence. MBio 2014;5:e01283-14.

[87] Brubaker L, Nager CW, Richter HE, et al. Urinary bacteria in adult women with urgency urinary incontinence. Int Urogynecol J 2014;25:1179-84.

[88] Thomas-White KJ, Hilt EE, Fok C, et al. Incontinence medication response relates to the female urinary microbiota. Int Urogynecol J 2016;27:723-33.

[89] Karstens L, Asquith M, Davin S, et al. Does the urinary microbiome play a role in urgency urinary incontinence and its severity? Front Cell Infect Microbiol 2016;6:78.

[90] Wu P, Chen Y, Zhao J, et al. Urinary microbiome and psychological factors in women with overactive bladder. Front Cell Infect Microbiol 2017;7:488.

[91] Pearce MM, Zilliox MJ, Rosenfeld AB, et al. The female urinary microbiome in urgency urinary incontinence. Am J Obstet Gynecol 2015;213:347.e1-11.

[92] Malykhina AP, Wyndaele JJ, Andersson KE, De Wachter S, Dmochowski RR. Do the urinary bladder and large bowel interact, in sickness or in health? ICI-RS 2011. Neurourol Urodyn 2012;31:352-8.

[93] Kaplan SA, Dmochowski R, Cash BD, Kopp ZS, Berriman SJ, Khullar V. Systematic review of the relationship between bladder and bowel function: implications for patient management. Int J Clin Pract 2013;67:205-16.

[94] Persson R, Wensaas KA, Hanevik K, Eide GE, Langeland N, Rortveit G. The relationship between irritable bowel syndrome, functional dyspepsia, chronic fatigue and overactive bladder syndrome: a controlled study 6 years after acute gastrointestinal infection. BMC Gastroenterol 2015;15:66.

[95] Matsumoto S, Hashizume K, Wada N, et al. Relationship between overactive bladder and irritable bowel syndrome: a large-scale internet survey in Japan using the overactive bladder symptom score and Rome III criteria. BJU Int 2013;111:647-52.

[96] Thompson WG, Drossman DA, Talley NJ, et al. Rome III diagnostic questionnaire for the 
adult functional GI disorders (including alarm questions) and scoring algorithm. In: Drossman DA, Corazziari E, Delvaux M, et al, editors. Rome III: the functional gastrointestinal disorders. ed. 3. McLean, VA: Degnon Associates; 2006. p. 917-51.

[97] Caremel R, Damon H, Ruffion A, et al. Can sacral neuromodulation improve minor incontinence symptoms in doubly incontinent patients successfully treated for major incontinence symptoms? Urology 2012;79:80-5.

[98] Booth J, Hagen S, McClurg D, et al. A feasibility study of transcutaneous posterior tibial nerve stimulation for bladder and bowel dysfunction in elderly adults in residential care. J Am Med Dir Assoc 2013;14:270-4.

[99] Lewis-Fernández R, Lam P, Lucak S, et al. An open-label pilot study of duloxetine in patients with irritable bowel syndrome and comorbid major depressive disorder. J Clin Psychopharmacol 2016;36:710-5.

[100] McLeod JG, Tuck RR. Disorders of the autonomic nervous system: Part 1. Pathophysiology and clinical features. Ann Neurol 1987;21:419-30.

[101] Blanc F, Pichot V, Roche F, Barthelemy JC, Tostain J. Activity of the autonomous nervous system measured based on the variability of heart rate in female urinary incontinence. Prog Urol 2001;11:492.

[102] Choi JB, Kim YB, Kim BT, Kim YS. Analysis of heart rate variability in female patients with overactive bladder. Urology 2005;65:1109-12.

[103] Hubeaux K, Deffieux X, Ismael SS, Raibaut P, Amarenco G. Autonomic nervous system activity during bladder filling assessed by heart rate variability analysis in women with idiopathic overactive bladder syndrome or stress urinary incontinence. J Urol 2007;178:24837.

[104] Hubeaux K, Deffieux X, Raibaut P, Le Breton F, Jousse M, Amarenco G. Evidence for autonomic nervous system dysfunction in females with idiopathic overactive bladder syndrome. Neurourol Urodyn 2011;30:1467-72.

[105] Ben-Dror I, Weissman A, Leurer MK, Eldor-Itskovitz J, Lowenstein L. Alterations of heart rate variability in women with overactive bladder syndrome. Int Urogynecol J 2012;23:10816.

[106] Aydogmus Y, Uzun S, Gundogan FC, Ulas UH, Ebiloglu T, Goktas MT. Is overactive bladder a nervous or bladder disorder? Autonomic imaging in patients with overactive bladder via dynamic pupillometry. World J Urol 2017;35:467-72.

[107] Ates E, Ipekci T, Akin Y, Kizilay F, Kukul E, Guntekin E. Impact of sympathetic dysfunction 
in the etiology of overactive bladder in women: a preliminary study. Neurourol Urodyn 2016; $35: 26-8$

[108] Nambiar AK, Bosch R, Cruz F, et al. EAU guidelines on assessment and nonsurgical management of urinary incontinence. Eur Urol 2018;73:596-609.

[109] Abrams P, Cardozo L, Wagg A, Wein A. 6th International Consultation on Incontinence; 2017.

[110] Drossaerts J, Vrijens D, Leue C, Schilders I, Van Kerrebroeck P, van Koeveringe G. Screening for depression and anxiety in patients with storage or voiding dysfunction: a retrospective cohort study predicting outcome of sacral neuromodulation. Neurourol Urodyn 2016;35:1011-6.

[111] Giarenis I, Musonda P, Mastoroudes H, Robinson D, Cardozo L. Can we predict detrusor overactivity in women with lower urinary tract symptoms? The King's Detrusor Overactivity Score (KiDOS). Eur J Obstet Gynecol Reprod Biol 2016;205:127-32.

[112] Hsiao SM, Lin HH, Kuo HC. The role of serum C-reactive protein in women with lower urinary tract symptoms. Int Urogynecol J 2012;23:935-40.

[113] Weissbart SJ, Bhavsar R, Rao H, et al. Specific changes in brain activity during urgency in women with overactive bladder after successful sacral neuromodulation: an fMRI study. J Urol 2018;200:382-8.

[114] Nardos R, Karstens L, Carpenter S, et al. Abnormal functional connectivity in women with urgency urinary incontinence: can we predict disease presence and severity in individual women using Rs-fcMRI/. Neurourol Urodyn 2016;35:564-73.

[115] Peyronnet B, Bendavid C, Manunta A, et al. The role of urinary markers in the assessment and follow-up of lower urinary tract disorders: a literature review. Prog Urol 2015;25:188-99.

[116] Birder LA, Ruggieri M, Takeda M et al. How does the urothelium affect bladder function in health and disease? ICI-RS 2011. Neurourol Urodyn 2012;31:330-8.

[117] Hashim H, Malmberg L, Graugaard-Jensen C, Abrams P. Desmopressin, as a "designer drug," in the treatment of overactive bladder syndrome. Neurourol Urodyn 2009;28:40-6. 
Fig. 1 - PRISMA flowchart. PRISMA = Preferred Reporting Items for Systematic Reviews and Meta-analyses.

Fig. 2 - The diagnosis "prism" approach of OAB phenotypes. The new diagnostic approach should seek for the underlying pathophysiological phenotypes, which could probably be achieved through a thorough clinical examination (though the clinical hallmarks of some phenotypes are still to be identified), eventually associated with urodynamics and other testing in selected cases. $\mathrm{OAB}=$ overactive bladder.

Fig. 3 - Paradigm shift in OAB management. (A) Current treatment algorithm. The current treatment strategies rely upon therapy invasiveness and cost rather than the appropriateness to patients' and symptom characteristics. (B) An idea of what the future treatment algorithm could look like, identifying underpinning mechanism to tailor treatment to individual patients' characteristics. What this figure does not perfectly reflect is that those phenotypes are not mutually exclusive and that they likely commonly overlap with certainly an interesting role for combination therapy. $A M=$ antimuscarinics; B3AG = beta-3 agonists; BFD = biofeedback; BHT = behavioural therapy; BTX = intradetrusor botulinum toxin injections; CIC = clean intermittent catheterisation; DLX = duloxetine; MUS = midurethral sling; OAB = overactive bladder; OMG = obesity management; PDE5i = phosphodiesterase inhibitors type 5; PFMT = pelvic floor muscle training; PTNS = posterior tibial nerve stimulation; $\mathrm{SNM}=$ sacral neuromodulation; VOT = vaginal oestrogen therapy. 
Figure 1

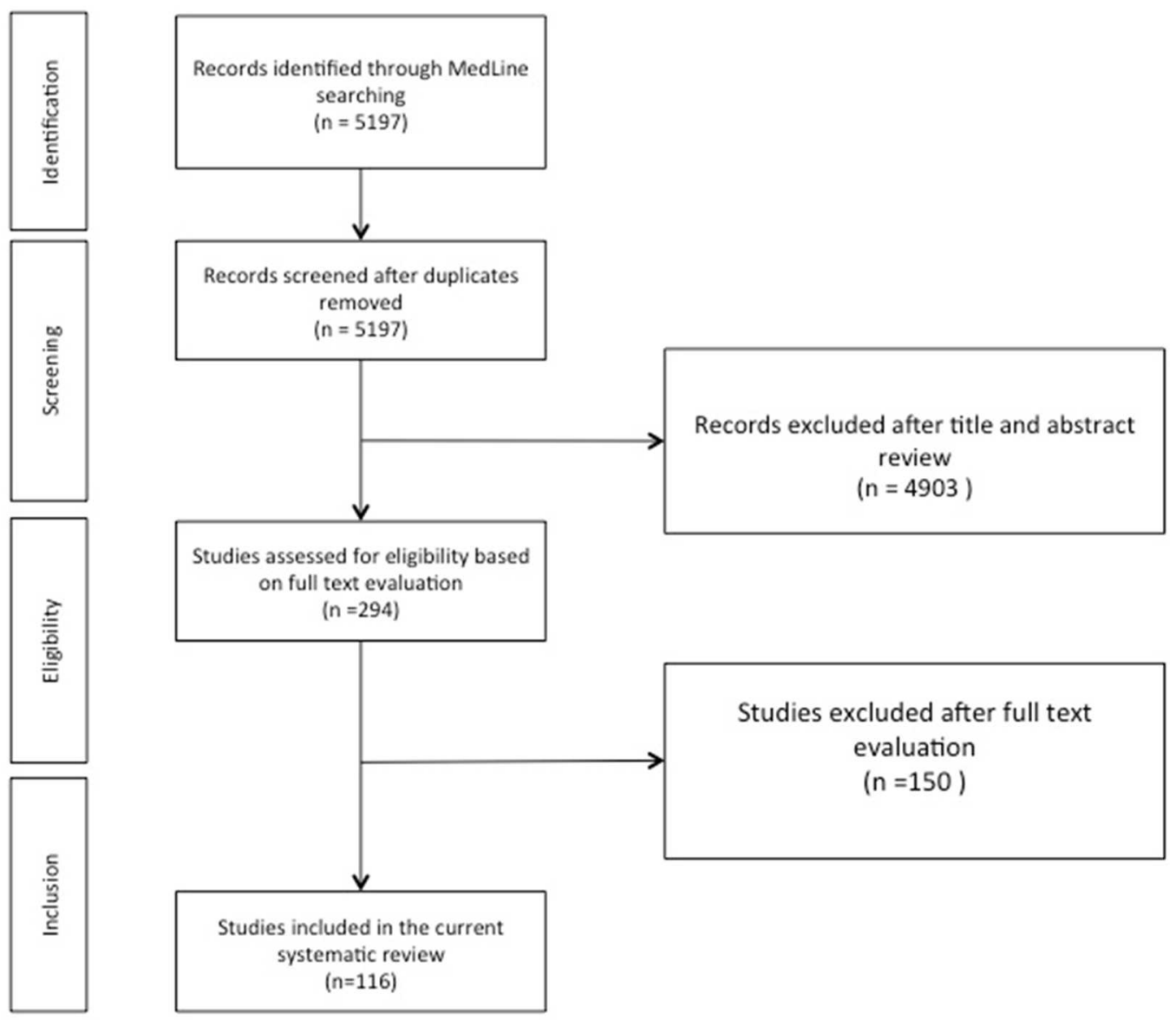


Figure 2

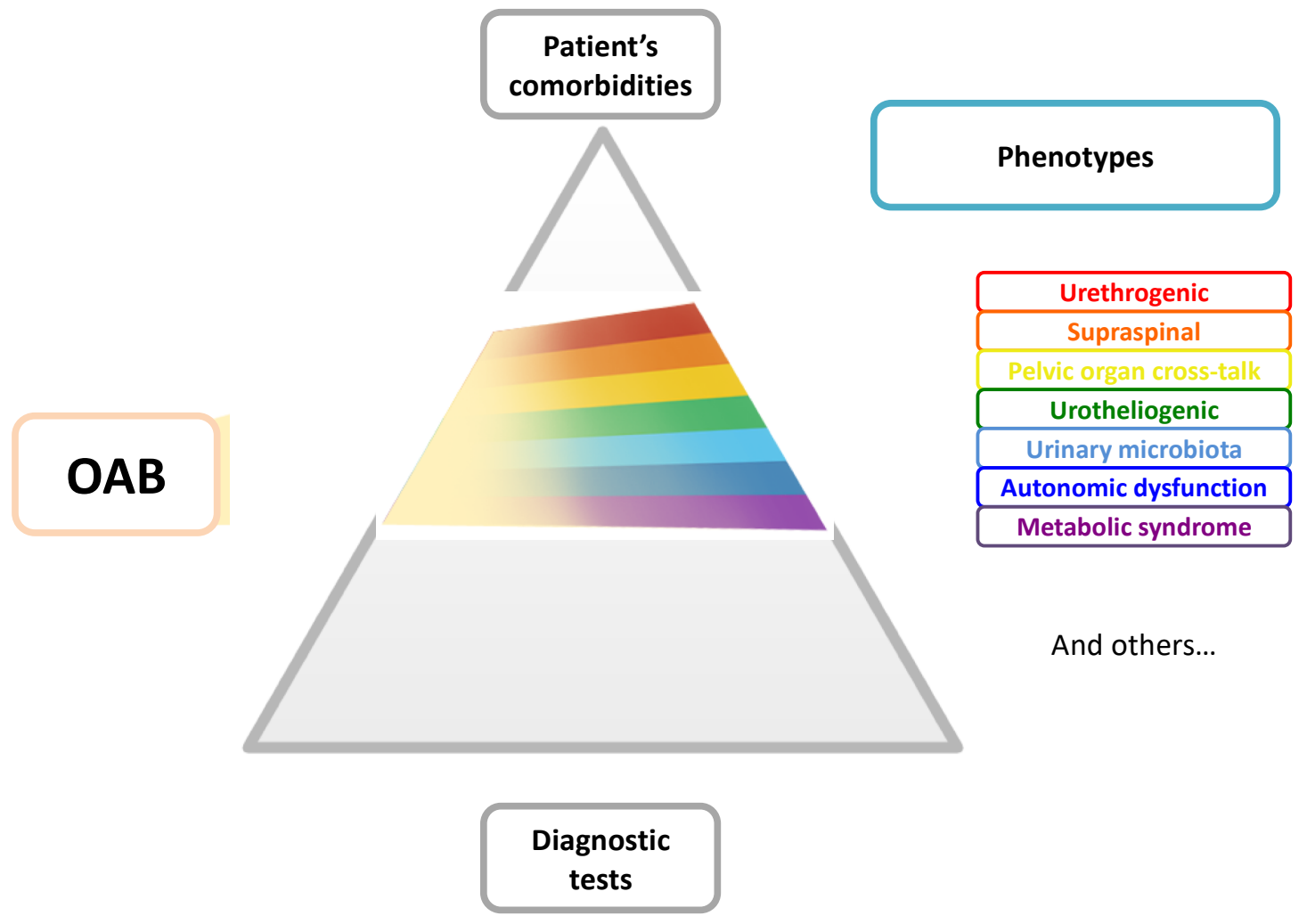




\section{Figure 3}

A

Overactive bladder

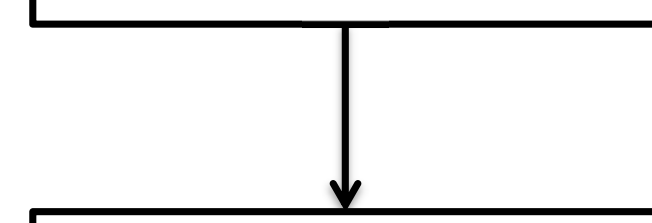

Behavioural interventions:

Bladder training, lifestyle modifications, ...

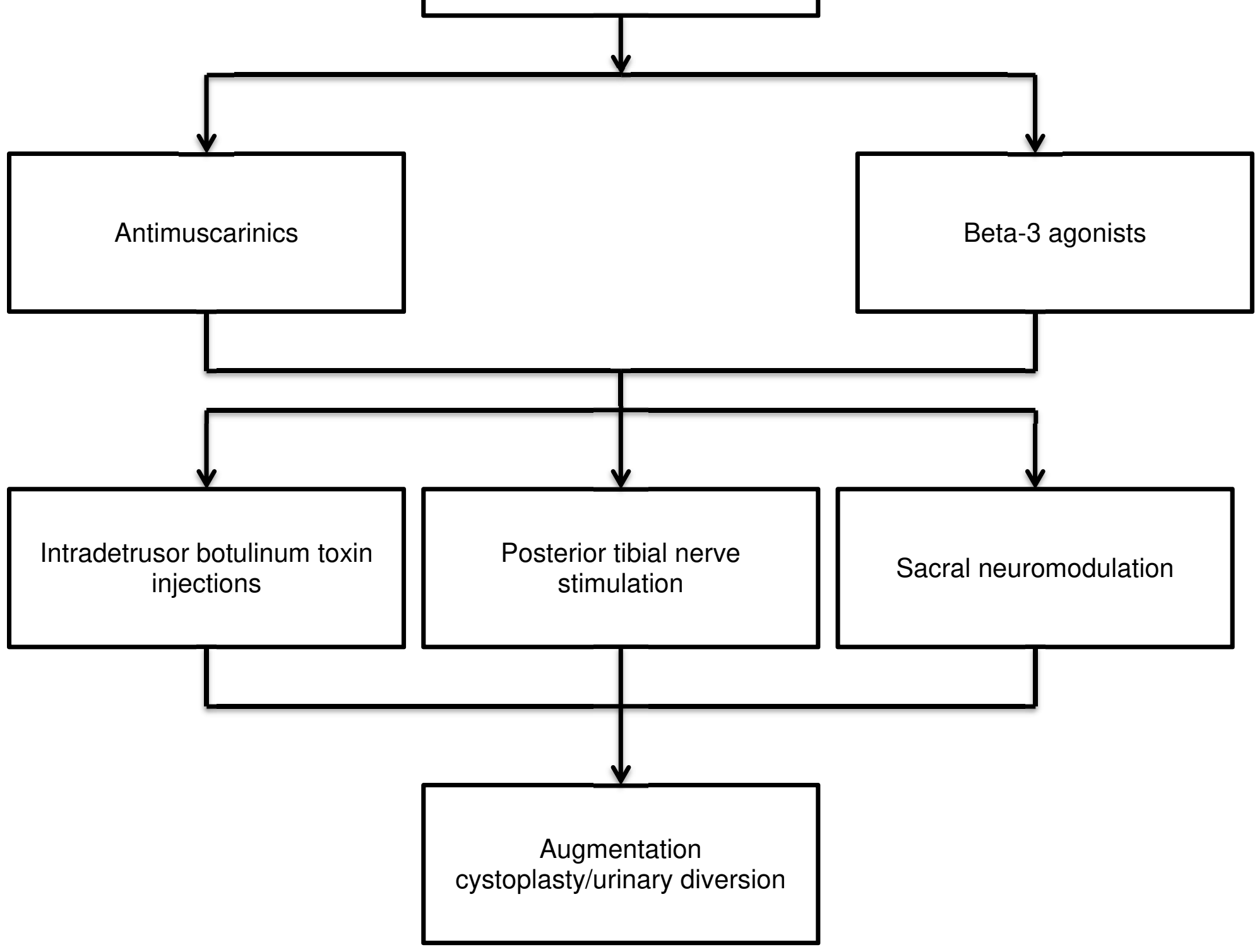


B

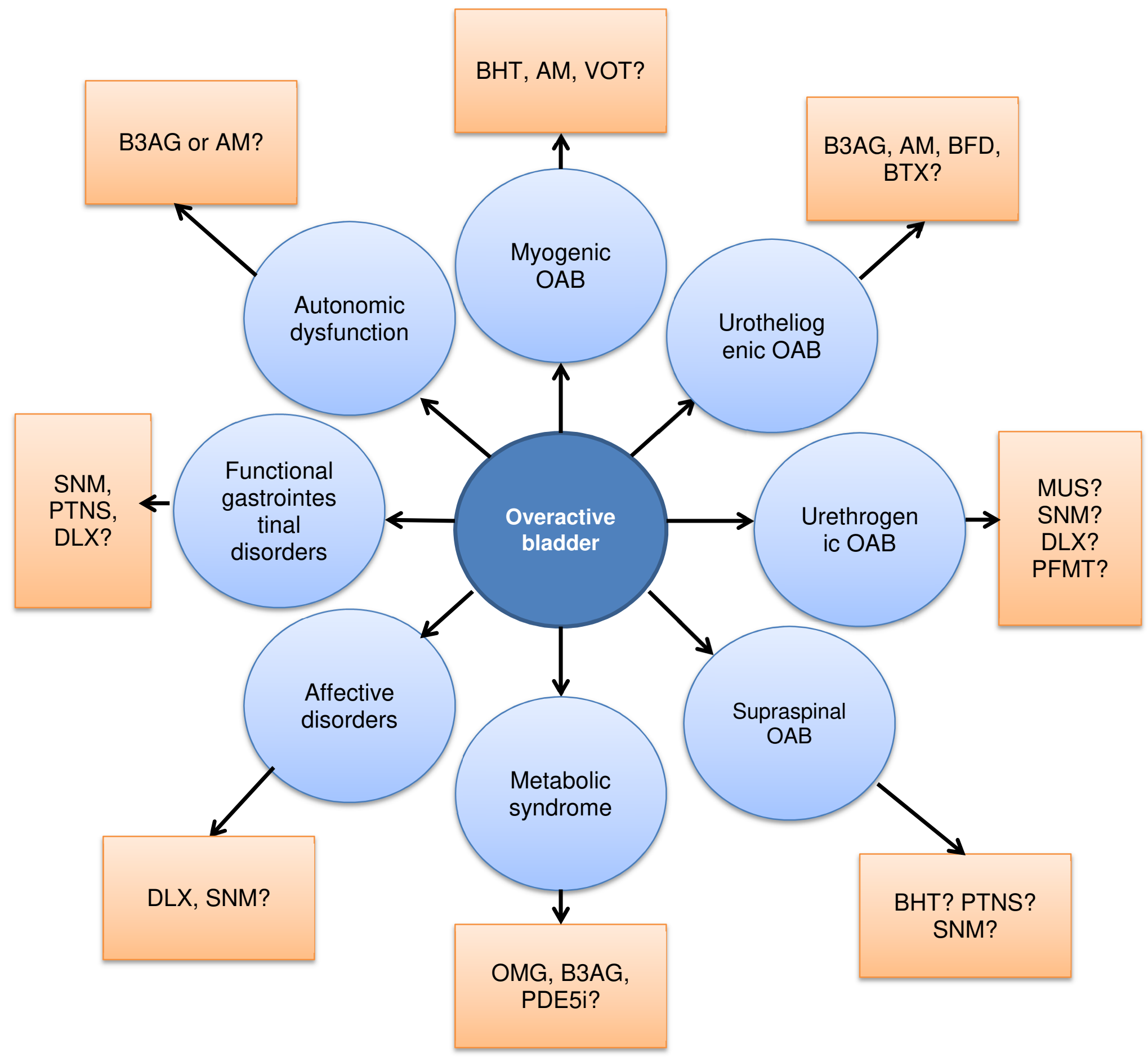


Table 1 - Possible OAB phenotypes

Phenotyping according to pathophysiological Phenotyping according to urodynamic factors demonstration of detrusor overactivity

Metabolic syndrome

Affective disorders

Sex hormone deficiency

Myogenic

Urotheliogenic

Urethrogenic

Urinary microbiota

Supraspinal

Functional gastrointestinal disorders

Autonomic nervous system dysfunction

Urotheliomyogenic: detrusor underactivity

$\mathrm{OAB}=$ overactive bladder 